\title{
Patrimônio cultural dos espaços religiosos afro-brasileiros: patrimônio subalterno? ${ }^{12}$
}

\author{
Patrimonio cultural de los espacios religiosos afro-brasileños: patrimonio \\ subalterno? \\ Cultural heritage of Afro-Brazilian religious spaces: subordinate \\ patrimony?
}

\author{
Walkyria Chagas da Silva Santos ${ }^{3}$
}

\begin{abstract}
Resumo
O objetivo deste trabalho é analisar o Patrimônio Cultural Negro guardado nos espaços religiosos afro-brasileiros como resistência as posturas colonizadoras do Estado, sendo pensado a partir das discussões sobre estética subalterna e o tombamento de terreiros. O Estado brasileiro começa a política de patrimonialização na década de 30. De 1937 até o início da década de 80 apenas monumentos que representavam os aspectos da estética arquitetônica elitista e portuguesa foram protegidos e preservados pelo Estado, a partir da aplicação do instituto do tombamento. Assim, os bens culturais de indígenas, negros e demais povos que participaram do processo de formação da sociedade brasileira foram excluídos_do âmbito de proteção. Quando na década de 80 ocorre o requerimento de tombamento do Ilê Axé Iyá Nassô Oká várias discussões são apresentadas para justificar a ausência de beleza e interesse em tombar o bem, para os conselheiros do Conselho Consultivo do Patrimônio Histórico e Artístico Nacional. Assim, havia o reconhecimento da necessidade de preservar o terreiro, porém, não era pacifico o entendimento de que seria cabível o tombamento, isto porque, muitos questionavam o que um terreiro possuía enquanto beleza arquitetônica que merecesse ser resguardado pelo Estado brasileiro. $\mathrm{O}$ tombamento do Ilê Axé Iyá Nassô Oká_ e a posterior promulgação da Constituição de 1988, que traz diversas garantias as minorias étnicas que representam uma estética rechaçada pelo Estado, trouxeram poucas modificações em termos práticos.
\end{abstract}

Palavras-Chave: Patrimônio Negro; Religiões Afro-brasileiras; Patrimônio subalterno.

\section{Resumen}

El objetivo de este trabajo es analizar el Patrimonio Cultural Negro guardado en los espacios religiosos afrobrasileños como resistencia a las posturas colonizadoras del Estado, siendo pensado a partir de las discusiones sobre estética subalterna y el tumbado de terreros. El gobierno brasileño comienza a patrimonialización política en la década de los 30. Desde 1937 hasta principios de los 80 únicos monumentos que representaban aspectos de la estética arquitectónica elitistas y portuguesas fueron preservados y protegidos por el Estado, de la aplicación de inclinar el instituto. Así, los bienes culturales de indígenas, negros y demás pueblos que participaron del proceso de formación de la sociedad brasileña fueron excluidos del ámbito de protección. Cuando en la década de 80 ocurre el requerimiento de tumbado del Ilê Axé Iyá Nassô Oká varias discusiones son presentadas para

\footnotetext{
1 Artigo apresentado no Simpósio Temático "Repensar, Refletir, Interpretar e Reinterpretar a Memória, identidade e o patrimônio cultural da América Colonial" durante o II Seminário Latino-Americano de Estudos em Cultura - SEMLACult, em Foz do Iguaçu/PR, Brasil, 2018.

${ }^{2}$ As discussões fazem parte da tese que será apresentada ao Programa de Pós-graduação em Estado e Sociedade da Universidade Federal do Sul da Bahia. A pesquisa é financiada pela Coordenação de Aperfeiçoamento de Pessoal de Nível Superior (CAPES).

${ }^{3}$ Mestra em Políticas Públicas e Segurança Social (UFRB); Doutoranda do Programa de Pós-Graduação em Estado e Sociedade, do Centro de Formação em Ciências Humanas e Sociais da Universidade Federal do Sul da Bahia (UFSB); Porto Seguro, Bahia, Brasil; Doutoranda em Direito, Faculdade de Direito da Universidade de Brasília (UnB); Brasília, Distrito Federal, Brasil; kyriachagas@yahoo.com.br.
} 
justificar la ausencia de belleza e interés en caer el bien, para los consejeros del Consejo Consultivo del Patrimonio Histórico y Artístico Nacional. Así, había el reconocimiento de la necesidad de preservar el terreiro, sin embargo, no era pacífico el entendimiento de que sería caber el caudal, porque muchos cuestionaban lo que un terreiro poseía como belleza arquitectónica que merecía ser resguardado por el Estado brasileño. El caos del Ilê Axé Iyá Nassô Oká y la posterior promulgación de la Constitución de 1988, que trae diversas garantías a las minorías étnicas que representan una estética rechazada por el Estado, han traído pocas modificaciones en términos prácticos.

Palabras claves: Patrimonio Negro; Religiones afrobrasileñas; Patrimonio subalterno.

\begin{abstract}
The objective of this work is to analyze the Black Cultural Heritage preserved in the Afro-Brazilian religious spaces as resistance to the colonizing positions of the State, being thought from the discussions about subalternative aesthetics and the landowning of terreiros. The Brazilian State began the policy of patrimonialization in the 1930s. From 1937 until the early 1980s only monuments that represented the aspects of the architectural aesthetics elitist and Portuguese were protected and preserved by the State, from the application of the institute of tipping. Thus, the cultural assets of indigenous, blacks and other peoples who participated in the process of formation of Brazilian society were excluded from the scope of protection. When in the 80's, Ilê Axé Iyá Nassô Oká's tipping request occurs, several discussions are presented to justify the absence of beauty and interest in overturning the good for the advisors of the National Historical and Artistic Heritage Advisory Council. Thus, there was recognition of the need to preserve the terreiro, however, it was not pacific the understanding that it would be appropriate to the tipping, because many questioned what a terreiro possessed as architectural beauty that deserved to be guarded by the Brazilian State. The overturning of Ilê Axé Iyá Nassô Oká and the subsequent promulgation of the 1988 Constitution, which brings diverse guarantees to ethnic minorities that represent an aesthetic rejected by the State, have brought few changes in practical terms.
\end{abstract}

Keywords: Black Heritage; Afro-Brazilian religions; Equity.

\title{
Introdução
}

O objetivo deste trabalho é analisar o Patrimônio Cultural Negro guardado nos espaços religiosos afro-brasileiros como resistência as posturas colonizadoras do Estado, sendo pensado a partir das discussões sobre estética subalterna e o tombamento de terreiros, em especial o processo de tombamento do Ilê Axé Iyá Nassô Oká (Terreiro da Casa Branca). O patrimônio cultural dos espaços religiosos afro-brasileiros é um patrimônio subalterno?

O Estado brasileiro começa a política de patrimonialização na década de 30 com a criação do Serviço do Patrimônio Histórico e Artístico Nacional (SPHAN), atualmente Instituto do Patrimônio Histórico e Artístico Nacional (IPHAN). De 1937 até o início da década de 80 apenas monumentos que representavam os aspectos da estética arquitetônica elitista e portuguesa foram protegidos e preservados pelo Estado, a partir da aplicação do 
instituto do tombamento. Portanto, a atuação estatal estava pautada no tombamento de patrimônio cultural que Fonseca (2003) denominou de patrimônio de "pedra e cal".

A denominação deriva do fato do órgão estatal brasileiro voltar o seu olhar essencialmente para o patrimônio material, em estilo barroco, que rememorava o período colonial e imperial da história do Brasil, mas rememora uma história bem marcada, a história dos colonizadores. Assim, os bens culturais de indígenas, negros e demais povos que participaram do processo de formação da sociedade brasileira foram excluídos do âmbito de proteção.

Quando na década de 80 ocorre o requerimento de tombamento do Ilê Axé Iyá Nassô Oká várias discussões são apresentadas para justificar a ausência de beleza e interesse em tombar o bem, para os conselheiros do Conselho Consultivo do Patrimônio Histórico e Artístico Nacional, o terreiro seria "desprovido de edificações de tivessem valor artístico, posto que, não apresentava a mesma suntuosidade das 'edificações religiosas, militares e civis da tradição luso-brasileira'”. (SANTOS, 2015).

Havia o reconhecimento da necessidade de preservar o terreiro, porém, não era pacifico o entendimento de que seria cabível o tombamento, isto porque, muitos questionavam o que um terreiro possuía enquanto beleza arquitetônica que merecesse ser resguardado pelo Estado brasileiro. Um dos grandes debates estava assentado no fato de que alguns conselheiros entendiam que não era possível tombar uma religião, porém, tal fato não foi impedimento para o tombamento dos espaços religiosos de matriz católica durante as décadas que sucederam a criação do SPHAN, fato relatado por Gilberto Velho (2012) parecerista do processo de tombamento do Ilê Axé Iyá Nassô Oká.

O tombamento do Ilê Axé Iyá Nassô Oká ocorrido em 1986 e a posterior promulgação da Constituição de 1988, que traz diversas garantias as minorias étnicas que representam uma estética rechaçada pelo Estado, trouxeram poucas modificações em termos práticos. Mossab (2016) informa que dos quase mil bens culturais arquitetônicos protegidos pelo IPHAN, aproximadamente $40 \%$ traz como referência estruturas religiosas de matriz católica, em contrapartida os bens arquitetônicos relacionados à memória dos afrodescendentes representa apenas $1 \%$ dos bens tombados. Portanto, o IPHAN continua priorizando a preservação de “edifícios de Estado e religiosos, de recorte colonial e elitista” (MOSSAB, 2016). 
O estudo sobre o ciclo das políticas públicas de proteção e preservação do patrimônio cultural das religiões afro-brasileiras "demonstra que ainda há dificuldade para que a questão da preservação dos Ilês Axés conquiste a agenda governamental. Houve janelas de oportunidades em 1986, 2000, 2005, 2008, 2013, 2014 e 2015, mas na verdade poucos terreiros são tombados de forma definitiva pelo IPHAN, em todo Brasil” (FERREIRA, 2018, p. 81). Em 2018 mais uma janela foi aberta resultando no tombamento de terreiros que lutavam pelo reconhecimento estatal quanto a sua importância religiosa e cultura, são eles o Tumba Junsara e o Ilê Obá Ogunté - Sítio de Pai Adão.

Assim, para analisar o Patrimônio Cultural Negro guardado nos espaços religiosos afro-brasileiros como resistência as posturas colonizadoras do Estado, o texto apresentará com brevidade o nascimento das políticas culturais no país e quais bens foram selecionados para representar a identidade da nação brasileira, portanto, qual estética foi escolhida para ser preservada. Ademais, abordará discussão sobre o patrimônio cultural dos terreiros a partir dos dados sobre tombamento do Ilê Axé Iyá Nassô Oká e sobre colonialidade. Nas considerações finais, pretende-se apresentar reflexões sobre a pergunta inicial, qual seja, "O patrimônio cultural dos espaços religiosos afro-brasileiros é um patrimônio subalterno?"

\section{Políticas Culturais no Brasil e a preservação do patrimônio cultural dos espaços religiosos afro-brasileiros}

As políticas culturais foram institucionalizadas no Brasil em 1937 com a criação do SPHAN, que a despeito de diversas contestações priorizou a preservação do patrimônio da cultura branca e elitizada e a estética barroca (RUBIM, 2007). O SPHAN foi criado para materializar a história nacional, auxiliar na "construção da nação brasileira", e o tipo de patrimônio escolhido para representar a nação brasileira constituía a produção artística e arquitetônica do período colonial, com ênfase para o patrimônio da região de Minas Gerais, tendo sete cidades tombadas. Portanto, foi priorizada a cultura material, com ênfase no patrimônio de origem portuguesa que "é explicada em função da força da sua cultura material, em detrimento da fragilidade material da cultura indígena ou da presença africana, em função da sua condição escrava”. (CHUVA, 2011, p.44). 
Até o início do século XX como foi visto não havia políticas culturais no Brasil e muito menos um patrão de história nacional a ser protegida. Foi o movimento modernista que mobilizou a construção dessa história. Até esse momento, a produção arquitetônica e artística do período colonial era pouco conhecida e valorizada, assim como, as expressões brasileiras do estilo barroco não recebiam atenção e proteção do Estado. E foi atualizando a linguagem artística em relação às vanguardas europeias que assumiram a missão de construir uma tradição cultural brasileira e o estilo barroco das edições e obras de artes coloniais foram considerados o primeiro estilo artístico genuinamente brasileiro. (FONSECA, 2007).

Fonseca aponta que a reinterpretação da arquitetura e da arte coloniais, e a leitura dos monumentos do passado era feita precariamente, e apresenta três motivos, são eles:

\begin{abstract}
Em primeiro lugar, pela falta de estudos históricos voltados para a civilização material do Brasil. Em segundo lugar, pelo fato de praticamente ainda não existirem no país estudos sistemáticos de história da arquitetura e da arte brasileira que apresentassem um inventário abrangente das obras e permitissem inclusive uma periodização dos estilos. E, finalmente, pelo fato de os vestígios materiais passíveis de serem tombados referirem primordialmente a tradição luso-brasileira, o que deixava à margem da representação da nação construída pelo conjunto de bens protegidos os testemunhos das duas outras raças formadoras da nacionalidade. (FONSECA, 2007, p. 168).
\end{abstract}

A partir de tal concepção, a maioria dos bens arquitetônicos escolhidos foram e são as construções religiosas, posto que, tais construções atendiam aos critérios que norteavam a ação do SPHAN e atualmente atendem aos critérios que norteiam o IPHAN, posto que, as construções religiosas representam a beleza e a verdade, por apresentar qualidade construtiva. (FERREIRA, 2018).

No âmbito internacional, após a Segunda Guerra Mundial, a proteção dos bens culturais considerados patrimônio da humanidade é inserida na agenda, tendo como responsável pela execução a Organização das Nações Unidas para a Educação, a Ciência e a Cultura(Unesco), que precisava da iniciativa dos Estados Nacionais. As políticas culturais, ou políticas de patrimônio para Unesco, apoiavam-se na Convenção do Patrimônio Mundial (1972) e estavam pautadas na diversidade cultural, considerada um dos principais recursos para uma cultura de paz. (FONSECA, 2007). 
No Brasil, com a Constituição de 1988, ocorre a ampliação do significado de patrimônio cultural, o seu âmbito e os instrumentos de proteção, pelo menos na esfera formal. Sobre a proteção do patrimônio imaterial, em 2000, ocorre a publicação do Decreto $\mathrm{n}^{\circ} 3.551$, que institui o Registro de Bens Culturais de Natureza Imaterial que constituem patrimônio cultural brasileiro e cria o Programa Nacional do Patrimônio Imaterial.

Segundo Fonseca, "o Registro dos bens culturais de natureza imaterial, voltado para a preservação de manifestações culturais de caráter processual, como os saberes, as celebrações, as formas de expressão e os lugares”. (FONSECA, 2007, p. 161). Tanto a Constituição de 1988 quanto o Decreto $\mathrm{n}^{\circ}$ 3.551/2000 informam que a preservação do patrimônio cultural brasileiro não cabe apenas ao Estado, mas também a sociedade. Ocorre que, o Estado continua sendo o grande protagonista das políticas culturais no Brasil. A partir de tal contexto surge o seguinte questionamento: quem determina o que é ou não é patrimônio cultural no Brasil? A partir de quais parâmetros?

Fonseca (2007) traz a tona a questão do papel dos bens culturais na transmissão da memória coletiva, que não possuem apenas valores econômicos, mas também simbólicos e afetivos.

[...] o Brasil "nasce" como uma colônia, ou seja, um "outro" que gravita em torno de um centro distante, a metrópole, centro esse que exerce sobre seu império um domínio político, econômico e cultural. Nesse sentido, as primeiras representações deste território foram produzidas por um olhar estrangeiro, a partir de padrões estéticos e de valores gerados em outros contextos. Coube aos viajantes europeus, que para cá vieram movidos pela curiosidade em relação a um mundo novo exótico e exuberante, produzir as primeiras imagens das paisagens e dos costumes que aqui encontraram. E foram essas imagens, em sua grande maioria guardadas em arquivos europeus, que consolidaram o modo como passamos a nos ver e também como somos vistos no exterior. [...] Os padrões que ditavam mentalidades, gostos e comportamentos eram os europeus, de que é exemplo ainda visível atualmente a arquitetura em estilo eclético no centro do Rio de Janeiro. (FONSECA, 2007, p. 166-167).

Quanto a baixa participação da sociedade no ciclo das políticas culturais, Aloisio Magalhães já apontava lá atrás, nas décadas de 70 e 80, os possíveis caminhos para aproximar a sociedade brasileira do patrimônio cultural, são eles: "buscar instrumentos para incluir no conjunto dos bens legalmente protegidos testemunhos das culturas indígenas e afro-brasileiras e abrir a prática política para a participação da sociedade”. (FONSECA, 2007, p. 168). 
E foi assim, preservando o patrimônio relacionado às memórias do poderio europeu, que o Brasil chegou à década de 80 com apenas um tombamento relacionado à cultura negra. Porém, o tombamento da Coleção de Magia Negra representou e representa mais um capítulo da violência sofrida pelos negros escravizados em solo brasileiro. Esta coleção não deveria existir, o Estado deveria buscar os descendentes dos proprietários dos bens e devolvê-los aos locais que sempre deveriam estar, nos locais de cultos, nos espaços de louvação aos orixás, voduns, inkices e entidades, nos espaços religiosos afro-brasileiros.

Portanto, é na década de 80 a partir de demanda e não espontaneamente, que o Estado brasileiro inicia o primeiro processo de individualização de um monumento negro para declará-lo patrimônio cultural nacional. Nas páginas do Processo $\mathrm{n}^{\circ} 1.067-\mathrm{T}-82$, processo administrativo de tombamento do Ilê Axé Iyá Nassô Oká é possível perceber as tensões e contradições que permeiam a sociedade brasileira, os ideias de branquitude/branquidade ${ }^{4}$, o racismo religioso $^{5}$, o colonialismo/colonialidade ${ }^{6}$ do patrimônio europeu.

A fissura na concepção de patrimônio cultural foi iniciada com o tombamento definitivo do Ilê Axé Iyá Nassô Oká em 1986, mas a sua garantia só foi formalizada na Constituição de 1988. O Texto Constitucional assegurou não só a igualdade e a liberdade religiosa (de culto, crença e organização religiosa), mas também o direito fundamental à cultura e a proteção do patrimônio cultural dos grupos que participaram da formação da sociedade brasileira. Vale ressaltar que, a inserção da proteção e preservação do patrimônio cultural das religiões afro-brasileiras e demais direitos relacionados à igualdade no exercício dos direitos foi resultado de séculos de lutas do povo negro, do povo de santo.

Mas, após mais de trinta anos da individualização do primeiro patrimônio negro, o tombamento definitivo do Ilê Axé Iyá Nassô Oká, as contradições permanecem, apenas 1\% dos bens tombados pelo IPHAN fazem referência a memória, ao patrimônio afro-brasileiro. Quais são os possíveis motivos? É o que tentaremos responder nas próximas linhas.

Antes de continuarmos o debate sobre as questões encontradas no processo de tombamento do Ilê Axé Iyá Nassô Oká precisamos esclarecer algumas questões sobre a

\footnotetext{
${ }^{4}$ CARDOSO, 2014; BENTO, 2002.

${ }^{5}$ NASCIMENTO, 2017.

${ }^{6}$ MALDONADO-TORRES, 2018.
} 
colonialidade. O conceito cunhado por Anibal Quijano e posteriormente ampliado por outros autores traz discussões sobre a continuidade de lógicas forjadas no período colonial nas seguintes áreas: econômicas, cognitivas, da existência, da cultura, etc. (BERNARDINOCOSTA, 2018). A colonialidade "pode ser compreendida como uma lógica global de desumanização que é capaz de existir até mesmo na ausência de colônias formais. (MALDONADO-TORRES, 2018, p. 36).

Portanto, a colonialidade que atua tanto no âmbito do saber, quanto do poder e do ser, e que se estende em vários âmbitos da vida do sujeito, também atua no âmbito cultural, para selecionar a estética que deve ser preservada pelo órgão cultural, assim os padrões, preferências são ditados para que a colonialidade seja permanente. Mas os povos explorados, subalternos sempre estiveram em movimento contra-hegemônico, buscando resguardar seus direitos e seu lugar na história.

Partindo da análise dos debates da Reunião de Conselheiros e Técnicos do SPHAN, em 1983, os técnicos reconheceram o significativo valor cultural do sítio, porém, a partir dos princípios que fundamentavam o tombamento dos bens que foram individualizados anteriormente, de origem europeia, que faziam referencia a cultura e estética branca, os técnicos apresentaram objeções ao tombamento do bem que não era compatível aos padrões e princípios dos bens de inspiração europeia. (FERREIRA, 2018).

Os Conselheiros do Conselho Consultivo do SPHAN seguiram o entendimento dos técnicos e debatiam que o tombamento de um terreiro não era possível, posto que, o bem era desprovido de edificações que tivessem valor artístico, que fossem suntuosos, assim, a construção dos templos religiosos afro-brasileiros eram consideradas inferiores. (FERREIRA, 2018). A desqualificação dos bens pelos técnicos e conselheiros do SPHAN demostra que a colonialidade continua presente na sociedade brasileira.

Para Wanderson Nascimento (2017) o racismo religioso é uma das marcas da colonialidade, que resulta na percepção de mundo que oprime e inferioriza os elementos constitutivos da população oprimida. Ao não perceber os espaços religiosos afro-brasileiros em toda sua complexidade, o Estado expõe as fraturas deixadas pelos processos de racialização que permeia as relações, o exercício do poder. Nas palavras do autor, 
E um dos primeiros gestos do racismo religioso é reduzir toda a complexidade dos modos de vida africanos que se mantém e se reorganizam nesses povos e comunidades a um caráter religioso, como se apenas fizessem rituais. Também fazem rituais, mas não é só isso! Simplificar toda uma matriz cultural (JESUS, 2003) a uma prática religiosa é construir uma "desculpa" para ocultar o racismo como ação política e deslocar a questão para o campo da "verdade" das disputas religiosas entre crenças hegemônicas e crenças inferiorizadas, atrasadas, falsas etc. [...]Trata-se, antes, de aliar à importante abordagem da chamada intolerância, o enfrentamento ao racismo que ataca as matrizes culturais que foram racializadas pelo processo histórico colonial, inferiorizando, exotizando e demonizando as práticas, saberes, valores experimentados nos terreiros. (NASCIMENTO, 2017, p. 55)

Assim, para Ferreira e Santos (2018), "O pedido de tombamento que representava a requisição de auxílio do Estado para preservação da cultura - que durante séculos foi perseguida pelos agentes estatais - transformou-se em mais uma "luta de resistência"". (FERREIRA, 2018, p. 77-78). Portanto, com a aplicação da lógica colonial e racista, a elite brasileira se mantem dizendo o que é direito ou não, quem tem o direito de viver ou morrer, o que é belo, qual tipo de estética deve prevalecer, qual bem deve ou não ser protegido, tombado pelo Estado.

\section{Conclusão}

Diante do exposto, é possível perceber que a despeito do reconhecimento da necessidade de preservar o patrimônio cultual do terreiro, não era pacifico o entendimento de que seria cabível o tombamento, isto porque, muitos questionavam o que um terreiro possuía enquanto beleza arquitetônica que merecesse ser resguardado pelo Estado brasileiro.

De 1986, ano do primeiro tombamento até hoje, ocorreram poucas modificações, dos quase mil bens culturais arquitetônicos protegidos pelo IPHAN, aproximadamente $40 \%$ traz como referência a estética de matriz católica, em contrapartida os bens arquitetônicos relacionados à memória dos afrodescendentes representa apenas $1 \%$ dos bens tombados. Portanto, o Estado brasileiro continua priorizando os bens que foram selecionados para representar a nação forjada no início do século XX, os bens do período colonial, mesmo com os novos paradigmas trazidos pela Constituição de 1988 que valoriza o pluralismo, a liberdade religiosa e a diversidade cultural.

Portanto, a partir do conceito de colonialidade é possível compreender que ainda hoje há a tentativa de invisibilizar a relevância da contribuição dos negros, de sua cultura e de sua 
religiosidade para identidade brasileira. Atualmente, há 11(onze) terreiros tombados definitivamente pelo IPHAN, são eles: Ilê Axé Iyá Nassô Oká (Terreiro da Casa Branca), Ilê Axé Opô Afonjá, Ilê Iyá Omi Axé Iyamassê (Terreiro do Gantois), Manso Banduquenque (Bate Folha), Ilê Maroiálaji Alakêto, Ilê Axé Oxumaré, e o Tumba Junsara, todos os terreiros citados estão localizados na cidade de Salvador/BA; na Bahia ainda temos o Zoogodo Bogum Malê Seja Undé (Terreiro Roça do Ventura), em Cachoeira e o Omo Ilê Agbôula na Ilha de Itaparica; e, há um terreiro no Maranhão, o Casa Grande de Minas ou Casa das Minas Jejê ou Querebentã de Zomadonu; e um terreiro em Recife, o Ilê Obá Ogunté - Sítio de Pai Adão.

A partir dos pontos que foram abordados fica claro que o patrimônio cultural dos espaços religiosos afro-brasileiros resulta numa estética subalterna cunhada coletivamente pelos diversos povos africanos escravizados no Brasil. Não subalterno como sinônimo de inferior, mas subalterno enquanto patrimônio que resiste às adversidades, que é questionador, insurgente. Seu reconhecimento não resulta da benevolência do Estado, e/ou de ações sem contradições, o reconhecimento do patrimônio cultural negro é resultado de um contexto de lutas do povo de santo.

A estética do terreiro que a primeira vista não representa o belo, o suntuoso para os técnicos e conselheiros do SPHAN/IPHAN é a estética da diáspora, do povo negro, das religiões que foram perseguidas e contra toda adversidade resistiu e mantem viva a tradição dos ancestrais. Os espaços religiosos afro-brasileiros contam a história da população negra que não é apresentada nos livros de história, na história oficial brasileira, portanto, é possível denominá-los de patrimônios de resistência, patrimônios diaspóricos, patrimônios subalternos.

\section{Referências}

BENTO, Maria Aparecida da Silva . Branqueamento e branquitude no brasil. In: CARONE, Iray; BENTO, Maria Aparecida da Silva (org.). Psicologia social do racismo: estudos sobre branquitude e branqueamento no Brasil. Rio de Janeiro: Editora Vozes, 2002.

BERNARDINO-COSTA, Joaze, MALDONADO-TORRES, Nelson; e, GROSFOGUEL, Ramón (Org.). Decolonialidade e pensamento afrodiaspórico. Belo Horizonte: Autentica Editora, 2018. 
CARDOSO, Lourenço. A branquitude acrítica revisitada e a branquidade. Revista da ABPN, v. 6, n. 13, mar. - jun. 2014, p. 88-106. Disponível em: $<$ http://www.abpnrevista.org.br/revista/index.php/revistaabpn1/article/view/152>. Acesso em: 03 mai. 2019.

FERREIRA, Maria Inês Caetano; SANTOS, Walkyria Chagas da Silva. Deixa a gira girar: proteção e preservação do patrimônio cultural das religiões afro-brasileiras. Revista de Políticas Públicas, v. 22, n. 1, 2018. Disponível em: <http://www.periodicoseletronicos.ufma.br/index.php/rppublica/article/view/9222/5482>.

Acesso em: 03 mai. 2019.

FONSECA, Maria C. Londres. Para além da pedra e cal: por uma concepção ampla de patrimônio. In: ABREU, Regina; CHAGAS, Mário (Org.). Memória e patrimônio: ensaios contemporâneos. Rio de Janeiro: DP\&A, 2003, p. 56-76.

O patrimônio histórico na sociedade contemporânea. Revista Escritos, Revista da Fundação Casa de Ruy Barbosa, Ano 1, $\mathrm{n}^{\circ}$ 1, 2007, p. 159-171. Disponível em: <http://www.casaruibarbosa.gov.br/escritos/numero01/FCRB_Escritos_1_7_Cecilia_Londres. pdf> Acesso: 03 mai. 2019.

MALDONADO-TORRES, Nelson. Analítica da colonialidade e da decolonialidade: algumas dimensões básicas. In: BERNARDINO-COSTA, Joaze, MALDONADO-TORRES, Nelson; e, GROSFOGUEL, Ramón (Org.). Decolonialidade e pensamento afrodiaspórico. Belo Horizonte: Autentica Editora, 2018.

MOASSAB, Andréia. O patrimônio arquitetônico no século 21: para além da preservação uníssona e do fetiche do objeto. Revista Arquitextos, ano 17, Nov. 2016. Disponível em: <http://www.vitruvius.com.br/revistas/read/arquitextos/17.198/6307> Acesso: 03 mai. 2019.

NASCIMENTO, Wanderson Flor do. O fenômeno do racismo religioso: desafios para os povos tradicionais de matrizes africanas. Revista Eixo, v. 6, n. 2 (Especial), novembro de 2017, p. 51-56. Disponível em: $<$ http://revistaeixo.ifb.edu.br/index.php/RevistaEixo/article/view/515/279 > Acesso: 03 mai. 2019.

SANTOS, Walkyria Chagas da Silva. Políticas públicas de reafricanização: tombamento dos terreiros de candomblé no estado da Bahia. 2015. 237f. Dissertação (Mestrado em Políticas Públicas e Segurança Social). Universidade Federal do Recôncavo da Bahia, Cruz das Almas, 2015.

VELHO, Gilberto. Patrimônio, negociação e conflito. In: AMORIM, Carlos A. [et al.]. Políticas de acautelamento do IPHAN para templos de Culto afro-brasileiros. Salvador: IPHAN, 2012, p. 55- 69. 